Int. J. Electrochem. Sci., 14 (2019) $9982-10001$

\title{
Photoelectrochemical degradation of methylene blue dye under visible light irradiation using $\mathrm{EG} / \mathrm{Ag}-\mathrm{ZrO}_{2}$ nanocomposite electrodes
}

\author{
Onoyivwe Monday Ama ${ }^{1,2}$, Anku William Wilson ${ }^{3, *}$, Suprakas Sinha Ray ${ }^{1,2}$ \\ ${ }^{1}$ Department of Chemical Sciences, University of Johannesburg, Doornfontein, 2028, Johannesburg, \\ South Africa. \\ ${ }^{2}$ DST-CSIR National Center for Nanostructured Materials, Council for Scientific and Industrial \\ Research, Pretoria 0001, South Africa. \\ ${ }^{3}$ CSIR- Water Research Institute, P. O. Box M.32, Accra, Ghana. \\ *E-mail: onoyivwe4real@gmail.com
}

doi: $10.20964 / 2019.10 .41$

Received: 6 June 2019 / Accepted: 9 July 2019 / Published: 30 August 2019

\begin{abstract}
The present study reports the application of three electrodes, consisting of exfoliated graphite (EG), EG and zirconium oxide $\left(\mathrm{EG}-\mathrm{ZrO}_{2}\right)$, and $\mathrm{EG}$ and silver-doped zirconium oxide $\left(\mathrm{EG} / \mathrm{Ag}-\mathrm{ZrO}{ }_{2}\right)$ in a comparative photoelectrochemical degradation of methylene blue (MB) dye in water under visible light irradiation. The $\mathrm{Ag}-\mathrm{ZrO}_{2}$ is prepared using a sol-gel method and used in the fabrication of EG/Ag- $\mathrm{ZrO} 2$ electrodes via a wet solution method. The morphologies, crystalline structures, and surface/physicochemical properties of the nanocomposites are characterized by SEM, TEM, XRD, and UV-Vis, FTIR, and Raman spectroscopies. The SEM results show that $\mathrm{ZrO}_{2}$ and $\mathrm{Ag}-\mathrm{ZrO} \mathrm{C}_{2}$ are evenly dispersed on the surfaces of EG. The XRD and Raman analyses reveal that $\mathrm{ZrO}_{2}$ exists in the tetragonal phase. The modification of $\mathrm{ZrO}_{2}$ with $\mathrm{EG}$ and $\mathrm{Ag}$ results in electrodes with strong absorption in the visible light region. All fabricated electrodes display the capacity to degrade $\mathrm{MB}$, with $\mathrm{EG} / \mathrm{Ag}-\mathrm{ZrO}{ }_{2}$ exhibiting the highest degradation efficiency and EG the lowest. The electrode with the highest efficiency $\left(\mathrm{EG} / \mathrm{Ag}-\mathrm{ZrO}_{2}\right)$ is used in optimization studies, which identify the optimum conditions required for maximizing the efficiency of the degradation process. In addition, the EG/Ag- $\mathrm{ZrO}$ is used in the degradation of $\mathrm{MB}$ via photolysis, as well as electrochemical and photoelectrochemical methods. The photoelectrochemical method exhibits superior performance when compared to photolysis and photocatalytic methods in the degradation of MB. The synergistic effects of $\mathrm{Ag}$ and $\mathrm{ZrO}_{2}$ enhance the efficiency of EG/Ag- $\mathrm{ZrO}_{2}$ toward the degradation of $\mathrm{MB}$.
\end{abstract}

Keywords: Exfoliated graphite, $\mathrm{Ag}, \mathrm{ZrO}_{2}$, electrode, photoelectrochemical degradation, dye 
(C) 2019 The Authors. Published by ESG (www.electrochemsci.org). This article is an open access article distributed under the terms and conditions of the Creative Commons Attribution license (http://creativecommons.org/licenses/by/4.0/). 